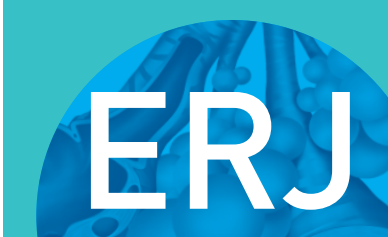

open research

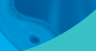

\title{
Endothelial dysfunction in COPD: a systematic review and meta-analysis of studies using different functional assessment methods
}

\author{
Marieta P. Theodorakopoulou (1) ', Maria Eleni Alexandrou', \\ Dimitra Rafailia Bakaloudi ${ }^{1}$, Georgia Pitsiou ${ }^{2}$, Ioannis Stanopoulos ${ }^{2}$, \\ Theodoros Kontakiotis ${ }^{3}$ and Afroditi K. Boutou $\mathbb{1}^{4}$
}

Affiliations: ${ }^{1}$ Dept of Nephrology, Hippokration Hospital, Aristotle University of Thessaloniki, Thessaloniki, Greece. ${ }^{2}$ Dept of Respiratory Failure, Aristotle University of Thessaloniki, Thessaloniki, Greece. ${ }^{3}$ Dept of Respiratory Medicine, Aristotle University of Thessaloniki, Thessaloniki, Greece. ${ }^{4}$ Dept of Respiratory Medicine, G. Papanikolaou Hospital, Thessaloniki, Greece.

Correspondence: Afroditi K. Boutou, Dept of Respiratory Medicine, G. Papanikolaou Hospital, Exohi, GR57010, Thessaloniki, Greece. E-mail: afboutoudyahoo.com

\section{ABSTRACT}

Background: Cardiovascular disease is a major cause of morbidity and mortality in COPD. Endothelial dysfunction is suggested to be one of the pathogenetic mechanisms involved. This is a systematic review and meta-analysis of studies using any available functional method to examine differences in endothelial function between patients with COPD and individuals without COPD (controls).

Methods: Literature search involved PubMed and Scopus databases. Eligible studies included adult patients and evaluated endothelial damage via functional methods. The Newcastle-Ottawa scale was applied to evaluate the quality of retrieved studies. Subgroup analyses were performed to explore heterogeneity across the studies. Funnel plots were constructed to evaluate publication bias.

Results: Of the 21 reports initially identified, 19 studies with a total of 968 participants were included in the final meta-analysis. A significantly impaired response in endothelium-dependent (weighted mean between-group difference (WMD) $-2.59,95 \% \mathrm{CI}-3.75$ to -1.42 ) and -independent vasodilation (WMD $-3.13,95 \%$ CI -5.18 to -1.09 ) was observed in patients with COPD compared to controls. When pooling all studies together, regardless of the technique used for assessment of vascular reactivity, pronounced endothelial dysfunction was observed in COPD compared to controls (standardised mean difference (SMD) $-1.19,95 \%$ CI -1.69 to -0.68 ). Subgroup analysis showed that the difference was larger when patients with COPD were compared with nonsmoking controls (SMD $-1.75,95 \%$ CI -2.58 to -0.92 ). Sensitivity analyses confirmed the results.

Conclusions: Patients with COPD have significantly impaired endothelial function compared to controls without COPD. Future studies should delineate the importance of endothelial dysfunction towards development of cardiovascular disease in COPD.

@ERSpublications

COPD is significantly associated with endothelial dysfunction of both conduit vessels and microvasculature. This association is further strengthened when patients with COPD are compared to nonsmoking controls. https://bit.ly/2NlWLFN

Cite this article as: Theodorakopoulou MP, Alexandrou ME, Bakaloudi DR, et al. Endothelial dysfunction in COPD: a systematic review and meta-analysis of studies using different functional assessment methods. ERJ Open Res 2021; 7: 00983-2020 [https://doi.org/10.1183/23120541.00983-2020].

This article has supplementary material available from openres.ersjournals.com

Received: 29 Dec 2020 | Accepted: 9 March 2021

Copyright $\odot$ The authors 2021. This version is distributed under the terms of the Creative Commons Attribution NonCommercial Licence 4.0. For commercial reproduction rights and permissions contact permissions@ersnet.org 


\section{Introduction}

COPD is a chronic inflammatory pulmonary disease characterised by partially reversible airflow obstruction, affecting $\sim 12 \%$ of the global population [1]. COPD is a major source of morbidity and mortality; death rates from COPD have been rising rapidly over the past decades, and it is now considered to be the third leading cause of death worldwide [2]. Cardiovascular disease contributes significantly to mortality and disease severity [3]. The degree of airflow obstruction is an independent predictor of adverse cardiovascular outcomes, such as myocardial infarction, stroke, congestive heart failure and sudden cardiovascular death $[4,5]$, insinuating a causal relationship between airflow limitation and cardiovascular disease [4].

Although cardiovascular disease and COPD share a major risk factor (i.e. smoking), and various common systemic manifestations, including diabetes mellitus, hypertension and obesity [6, 7], the underlying mechanisms have not been fully established. Among the latter, chronic systemic inflammation, oxidative stress, chronic hypoxia, arterial stiffness and endothelial dysfunction are proposed to significantly affect the link between these two entities [8]. In fact, endothelial dysfunction is shown not only to contribute to the development of cardiovascular disease in this population, but is also related to COPD severity [9]. Moreover, ageing could be another potential link. Vascular endothelial dysfunction occurs during the human ageing process and is accompanied by deterioration in the balance between vasodilator and vasoconstriction substances produced by the endothelium; pathophysiological mechanisms include alterations related to oxidative stress, changes in pro-inflammatory cytokines levels and senescence of endothelial cells [10]. As hallmarks of accelerated ageing and lung cell senescence, including telomere shortening, genomic instability, mitochondrial dysfunction and stem cell exhaustion are all observed in various proportions in COPD lungs, the "ageing hypothesis" for COPD has been developed, suggesting that this syndrome, with both respiratory and systemic manifestations, represents a manifestation of accelerated ageing [11, 12]. Furthermore, endothelial dysfunction manifested in the pulmonary vessels plays a central role in pulmonary arterial hypertension development [9], a condition that further exacerbates morbidity and mortality in COPD [13].

Endothelial dysfunction, defined as a state of imbalance between endothelium-derived relaxing and contracting factors, is the earliest stage of atherosclerosis [14]. Starting from the very invasive method of the epicardial coronary angiography after intracoronary infusion of vasoactive drugs, several less invasive functional techniques (i.e. venous occlusion plethysmography (VOP), forearm flow-mediated dilatation (FMD), peripheral arterial tonometry (PAT), nailfold capillaroscopy, laser-speckle contrast imaging/ analysis (LSCI/LASCA), etc.) and biomarkers (i.e. asymmetric dimethylarginine, endothelial microparticles, inflammation markers, etc.) have been used to evaluate peripheral endothelial function in individuals with high cardiovascular risk [14]. Despite the fact that all these techniques have boosted the research in this field, none of them has been established as a diagnostic tool for cardiovascular events prediction in daily clinical practice so far [15]. In COPD, FMD is the most widespread used functional method for peripheral endothelial function assessment, whereas in the recent years the application of PAT has gained more ground due to its noninvasive and operator-independent nature [16].

Previous meta-analyses in the field conducted some years ago demonstrated that patients with COPD had impaired endothelial function compared to controls, and that this decline was proportionally associated with the degree of airway obstruction $[17,18]$. Despite their interesting results, these works carried some important methodological errors in the design and execution of the meta-analysis (e.g. double counts and units-of-analysis errors) and included studies that used only FMD for endothelial function assessment $[17,18]$. FMD examines the function of conduit arteries, but does not provide information about microvascular function and hyperaemia within the tissue itself (assessed by other methods, e.g. PAT, LASCA, near-infrared spectroscopy, etc.) $[15,19]$. Furthermore, although FMD is correlated with coronary endothelial function, it has been suggested that microvascular dysfunction may be an earlier indicator of cardiovascular risk [15]. In light of the above, we conducted an updated systematic review and meta-analysis of studies using any available functional method to examine differences in endothelial function between patients with COPD and individuals without COPD.

\section{Materials and methods}

This systematic review and meta-analysis was conducted in accordance with the Preferred Reporting Items for Systematic Reviews and Meta Analyses and the Meta Analysis of Observational Studies in Epidemiology guidelines (supplementary table 1). All research was conducted according to a protocol submitted to the PROSPERO database (www.crd.york.ac.uk/PROSPERO/ identifier number CRD42021225836).

\section{Search strategy and eligibility criteria}

A systematic literature search was conducted in the PubMed and Scopus databases (from database inception to 25 November 2020), using a combination of free-text terms and relevant Medical Subject Headings (MeSH). Keywords and an example of our search strategy used in PubMed are presented in 
supplementary table 2. Manual checking of reference lists of retrieved articles and reports, including relevant reviews and meta-analyses was performed to identify additional and potentially relevant articles. Observational studies (cohorts, case-control and cross-sectional studies) assessing endothelial function in patients with COPD compared to controls (healthy individuals or patients with concomitant diseases other than COPD), as well as clinical trials (if a control group was included at baseline and relevant baseline comparisons were available) were considered eligible. All types of semi-invasive and noninvasive functional methods based on Doppler ultrasound, plethysmography, laser Doppler, near-infrared spectroscopy or novel techniques, based on optical coherence techniques for assessment of endothelial damage (FMD, nitroglycerine-mediated dilatation (NMD), PAT, laser-doppler flowmetry (LDF), VOP, LASCA, nailfold capillaroscopy, near-infrared spectroscopy, arterial glycocalyx) were included. In our inclusion criteria, we accepted studies evaluating endothelial function of both conduit arteries and microvessels. Pre-clinical studies, studies with nonadult patients, studies evaluating endothelial dysfunction via serum biomarkers or invasive methods and studies evaluating endothelial function during acute exacerbation were excluded. The search strategy was developed with English language restriction.

\section{Study selection and data extraction}

Two authors (MT, DB) examined thoroughly the titles and abstracts of records retrieved throughout the search, and then independently performed full-text assessment to identify eligible studies, unblinded to the records' authors and institutions. A data extraction form designed according to the Cochrane checklist of items, containing fields for all important data on study design, demographics, outcome measurements and details relevant to quality assessment was completed for each eligible study by the two authors. All disagreements on study selection and data collection were solved by a third senior reviewer (MA). In cases of missing data, study authors were contacted by e-mail to try to retrieve original data.

\section{Quality assessment tool}

Assessment of the quality of the eligible studies was performed by the two reviewers (MT, DB) according to the Newcastle-Ottawa scale (NOS), a tool developed for quality assessment of nonrandomised studies, with a different scale corresponding to every study's design (cohort or case-control studies) [20]. The NOS is a nine-point scale that involves the appraisal of methodological issues and their reporting. The scoring system encompasses three major domains (participant selection, group comparability and ascertainment of exposure); scores range from 0 to 9 , with scores $\geqslant 7$ indicating high-quality studies (supplementary table 3 ).

\section{Statistical analyses}

For studies assessing endothelial function using the same method, the weighted-mean between-group difference (WMD) was calculated with pertinent $95 \%$ confidence intervals when data were expressed in the same measurement scale (proportional change from baseline, $\mathrm{mL} \cdot \mathrm{min}^{-1}$ per $100 \mathrm{~mL}$ tissue). When data from different studies corresponding to the same method were expressed in different measurement scales or when pooling all available data from all types of methods of functional evaluation of endothelial damage, the respective standardised mean difference (SMD) with 95\% confidence intervals was used. For all studies (including all methods of assessment), subgroup analysis was performed on the basis of sex, presence of coronary artery disease (CAD) and controls' smoking status. Finally, we planned to explore robustness of our findings by means of a sensitivity analysis excluding studies judged as poor quality $(\mathrm{NOS}<7)$. For studies reporting median and range or interquartile range values, we calculated mean $\pm \mathrm{SD}$ values based on relevant formulas [21]. For studies including multiple comparator groups (e.g. group 1: patients with COPD and CAD; group 2: patients with COPD without CAD; group 3: controls with CAD; group 4: controls without $\mathrm{CAD}$ ), all relevant groups were combined to create a single pair-wise comparison in order to avoid a unit-of-analysis error [22]. Similarly for subgroup analysis with a shared group (e.g. patients with COPD) and different comparator groups (smoker and nonsmoker controls), shared group was divided out approximately evenly among subgroup comparisons [22]. When pooling all available data from the total of studies in order to calculate the SMD, for those studies assessing endothelial function with more than one method, data reported from one method exclusively were included.

We evaluated statistical heterogeneity across studies using Cochran's $Q$ test $(p<0.1$ indicating existence of heterogeneity) along with the $\mathrm{I}^{2}$ statistic (with a result $>50 \%$ suggesting significant heterogeneity). A funnel plot of all studies assessing endothelial function was examined for the presence of asymmetry. The random-effects meta-analytic model was used to combine our data due to the existence of high clinical and methodological between-study heterogeneity. The inverse-variance method was used to estimate study weights, but with shared intervention groups divided out approximately evenly among the comparisons. Statistical analyses were performed using Review Manager (RevMan, version 5.3). 


\section{Results}

Search results

The study selection process is presented as flow diagram in supplementary figure 1 . The searches identified in total 1726 reports; after removing duplicates $(n=395), 1331$ studies were screened at a title/ abstract level. Following the assessment of 50 full-text reports, we excluded 29. Hence, 21 studies enrolling 638 patients with COPD and 595 controls were included in this systematic review. Of the 21 studies, only 19 studies (with 968 participants) [23-41] were included in the quantitative analysis, since available data for the other two were inadequate $[42,43]$. The authors were contacted by email requesting supplementary data, with one of them responding [35].

\section{Quality assessment}

Our search did not identify any cohort or cross-sectional studies, so the NOS for case-control studies was used. The overall study quality assessment for studies included in this analysis is depicted in supplementary table 3 . According to the NOS score, 16 studies where classified as high quality (NOS $\geqslant 7$ ) and the remaining three studies as low quality $[25,28,29]$.

\section{Publication bias}

As presented in supplementary figure 2, asymmetry in the funnel plot suggests that some small studies with nonsignificant results might be missing, therefore indicating that the possibility of publication bias could not be excluded.

\section{Study characteristics}

Of the 21 studies included in this systematic review, 16 studies evaluated endothelial function only via FMD (eight used NMD) [28-43], two only via VOP (forearm blood flow (FBF) assessment after bradykinin infusion) $[23,24]$, one study via FMD and VOP (FBF after a typical post-occlusion reactive hyperaemia protocol) [25], one study via PAT [26] and one study via flow-mediated skin fluorescence (FMSF) [27]. Seven studies included patients with COPD, without overt cardiovascular disease [23, 26, $31-33,39,40]$ and one study included patients with co-existing COPD and CAD [25]. Regarding sex distribution, four studies included only male participants [23-25, 43], while no study was conducted only in female patients. Table 1 and supplementary table 4 show the characteristics of the studies included.

\section{Endothelial function assessment via FMD}

Across 15 studies evaluating endothelial function by measuring FMD of the brachial artery, a significantly lower endothelium-dependent vasodilatation of WMD -2.59 (95\% CI -3.75 to -1.42 ) was observed in patients with COPD compared to controls, but with high heterogeneity across studies $\left(\mathrm{I}^{2}=96 \%, \mathrm{p}<0.00001\right)$ (figure 1a).

\section{Endothelial function assessment via PAT}

Only one study explored endothelial function via PAT in patients with COPD and healthy controls, showing a markedly impaired reactive hyperaemia index in the former (figure 1b).

\section{Endothelial function assessment via VOP in the forearm}

Only one study evaluated FBF during reactive hyperaemia (figure 1c), without noting significant differences between patients with COPD and controls (COPD $9.8 \pm 4.6 \mathrm{~mL} \cdot \mathrm{min}^{-1}$ per $100 \mathrm{~mL}$ tissue versus control $8.9 \pm 3.8 \mathrm{~mL} \cdot \mathrm{min}^{-1}$ per $100 \mathrm{~mL}$ tissue; $\left.\mathrm{p}=0.577\right)$. Across the two studies evaluating $\mathrm{FBF}$ after bradykinin infusion, calculation of a WMD between patients with COPD and controls could not be performed due to differences in measurement scales of reported results, so data had to be pooled using SMD. No significant differences in FBF were observed between the patients with COPD and controls (SMD $-2.31,95 \%$ CI -7.08 to $2.44 ; \mathrm{I}^{2}=96 \%, \mathrm{p}<0.00001$ ) (figure 1c). Overall, endothelium-dependent vasodilation (expressed via FBF after reactive hyperaemia or bradykinin infusion) was nonsignificantly lower in COPD, compared to controls (SMD -1.31, 95\% CI -3.28 to 0.67) (figure 1c).

\section{Endothelial function assessment via FMSF}

As expected due to the novelty of the method, only one study has used FMSF to assess endothelial function in COPD, reporting that hyperaemic response did not differentiate between the two study groups (-3.70, 95\% CI -9.01 to 1.61 ) (figure $1 \mathrm{~d}$ ). 
TABLE 1 Characteristics of studies included in this systematic review and meta-analysis

\begin{tabular}{|c|c|c|c|c|c|c|c|c|c|c|c|}
\hline \multirow{2}{*}{$\begin{array}{l}\text { First author, year } \\
\text { [ref.] }\end{array}$} & \multirow{2}{*}{$\begin{array}{l}\text { Assessment } \\
\text { method }\end{array}$} & \multirow{2}{*}{$\begin{array}{l}\text { Measurements } \\
\text { and scale }\end{array}$} & \multicolumn{5}{|c|}{ COPD } & \multicolumn{4}{|c|}{ Controls } \\
\hline & & & $\begin{array}{c}\text { Subjects } \\
\mathrm{n}\end{array}$ & $\begin{array}{l}\text { Age } \\
\text { years }\end{array}$ & $\begin{array}{c}\text { Male } \\
\%\end{array}$ & $\begin{array}{c}\text { FEV }_{1} \\
\%\end{array}$ & CVD $^{\#}$ & $\begin{array}{c}\text { Subjects } \\
n\end{array}$ & $\begin{array}{l}\text { Age } \\
\text { years }\end{array}$ & $\begin{array}{c}\text { Male } \\
\%\end{array}$ & Smoking status \\
\hline BARAK, 2017 [30] & FMD & $\begin{array}{l}\text { FMD\% (\% proportional } \\
\text { change from baseline) }\end{array}$ & 17 & $69.0 \pm 8.1$ & 64.7 & $31.8 \pm 11.0$ & 5.9 & 10 & $65.3 \pm 7.3$ & 70.0 & $\begin{array}{c}\text { Former smokers } \\
n=4 ; \\
\text { nonsmokers } n=6\end{array}$ \\
\hline BARR, 2007 [42] & FMD & $\begin{array}{l}\text { FMD\% (\% proportional } \\
\text { change from baseline) }\end{array}$ & 44 & $\mathrm{n} / \mathrm{a}$ & 54.5 & $\mathrm{n} / \mathrm{a}$ & $\mathrm{n} / \mathrm{a}$ & 63 & $70.0 \pm 5.0$ & 54.0 & Former smokers \\
\hline Вцим, 2014 [28] & FMD & $\begin{array}{l}\text { FMD } \% \text { ( } \% \text { proportional } \\
\text { change from baseline) }\end{array}$ & 23 & $64.4 \pm 8.4$ & 56.0 & $45.0 \pm 14.0$ & 26.0 & 22 & $44.7 \pm 11.7$ & 46.0 & Nonsmokers \\
\hline Costanzo, 2017 [29] & FMD & $\begin{array}{l}\text { FMD\% (\% proportional } \\
\text { change from baseline) }\end{array}$ & 41 & $74.0 \pm 5.8$ & 56.1 & $61.9 \pm 16.6$ & $\begin{array}{l}\mathrm{n} / \mathrm{a}(0 \% \mathrm{CAD} \text {, } \\
\text { but data about } \\
\text { PAD and } \\
\text { stroke } \\
\text { missingl }\end{array}$ & 35 & $73.8 \pm 6.6$ & 45.7 & $\mathrm{n} / \mathrm{a}$ \\
\hline ЕІскноғF, 2008 [31] & $\begin{array}{l}\text { FMD and } \\
\text { NMD }\end{array}$ & $\begin{array}{c}\text { FMD } \% \text { and NMD\% }(\% \\
\text { proportional change from } \\
\text { baseline) }\end{array}$ & 60 & $62.0 \pm 8.0$ & 56.6 & $41.0 \pm 18.0$ & 0 & 40 & $60.9 \pm 10.4$ & 37.5 & $\begin{array}{c}\text { Nonsmokers } \mathrm{n}=20 \text {; } \\
\text { smokers } \mathrm{n}=20\end{array}$ \\
\hline GeLINAS, 2017 [32] & $\begin{array}{l}\text { FMD and } \\
\text { NMD }\end{array}$ & $\begin{array}{c}\text { FMD } \% \text { and NMD\% (\% } \\
\text { proportional change from } \\
\text { baseline) }\end{array}$ & 24 & $69.9 \pm 2.8$ & 54.2 & $68.0 \pm 19.0$ & 0 & 20 & $62.6 \pm 1.1$ & 50.0 & $\begin{array}{l}\mathrm{n} / \mathrm{a} \text { (excluded if } \\
>10 \text { pack-years) }\end{array}$ \\
\hline HARTMANN, 2016 [33] & $\begin{array}{l}\text { FMD and } \\
\text { NMD }\end{array}$ & $\begin{array}{c}\mathrm{FMD} \% \text { and } \mathrm{NMD} \%(\% \\
\text { proportional change from } \\
\text { baselinel }\end{array}$ & 10 & $67.0 \pm 3.0$ & 40.0 & $60.0 \pm 5.0$ & 0 & 10 & $66.0 \pm 2.0$ & 40.0 & Nonsmokers \\
\hline IVES, 2014 [34] & FMD & $\begin{array}{l}\text { FMD\% (\% proportional } \\
\text { change from baseline) }\end{array}$ & 30 & $66.0 \pm 2.0$ & 50.0 & $55.0 \pm 4.0$ & 6.66 & 30 & $66.0 \pm 2.0$ & 50.0 & Nonsmokers \\
\hline KeYMEL, 2018 [25] & $\begin{array}{l}\text { FMD and } \\
\text { NMD, VOP }\end{array}$ & $\begin{array}{c}\mathrm{FMD} \%, \mathrm{NMD} \% \text { (\% } \\
\text { proportional change from } \\
\text { baseline) and FBF after } \\
\text { reactive hyperaemia } \\
\text { ( } \mathrm{mL} \cdot \mathrm{min}^{-1} \text { per } 100 \mathrm{~mL} \text { tissue) }\end{array}$ & 17 & $66.0 \pm 8.0$ & 100 & $59.0 \pm 17.0$ & 100.0 & 16 & $64 \pm 10.0$ & 100 & $\begin{array}{l}\text { Former smokers } \\
\qquad \mathrm{n}=16\end{array}$ \\
\hline Kuzuвova, 2013 [43] & FMD & $\begin{array}{l}\text { FMD\% (\% proportional } \\
\text { change from baseline) }\end{array}$ & 63 & $60.4 \pm 1.0$ & 100 & $45.1 \pm 2.4$ & $\mathrm{n} / \mathrm{a}$ & 95 & $57.3 \pm 1.7$ & 100 & $\begin{array}{l}57 \% \text { former or } \\
\text { current smokers }\end{array}$ \\
\hline MACLAY, 2009 [23] & VOP & $\begin{array}{l}\text { FBF after bradykinin infusion } \\
\left(\mathrm{mL} \cdot \mathrm{min}^{-1} \text { per } 100 \mathrm{~mL} \text { tissue) }\right.\end{array}$ & 18 & $65.0 \pm 5.4$ & 100 & $47.6 \pm 20.1$ & 0 & 17 & $63.0 \pm 6.0$ & 100 & Nonsmokers \\
\hline MAJEWSKI, 2020 [27] & FMSF & $\begin{array}{l}\text { Reactive hyperaemia ( } \% \\
\text { proportional change from } \\
\text { baseline) }\end{array}$ & 26 & $66.9 \pm 8.3$ & 42.3 & $63.7 \pm 13.1$ & 7.69 & 20 & $52.5 \pm 13.2$ & 60.0 & $\begin{array}{c}\text { Smokers } n=2 ; \\
\text { former smokers } \\
n=3 ; \\
\text { nonsmokers } n=15\end{array}$ \\
\hline MaLerba, 2018 [26] & PAT & $\mathrm{RHI}$ & 16 & $74.2 \pm 8.6$ & 62.5 & $69.5 \pm 19.0$ & 0 & 16 & $75.1 \pm 3.2$ & 62.5 & $\begin{array}{c}\text { Smokers } n=3 ; \\
\text { former smokers } \\
n=7 ; \\
\text { nonsmokers } n=6\end{array}$ \\
\hline
\end{tabular}




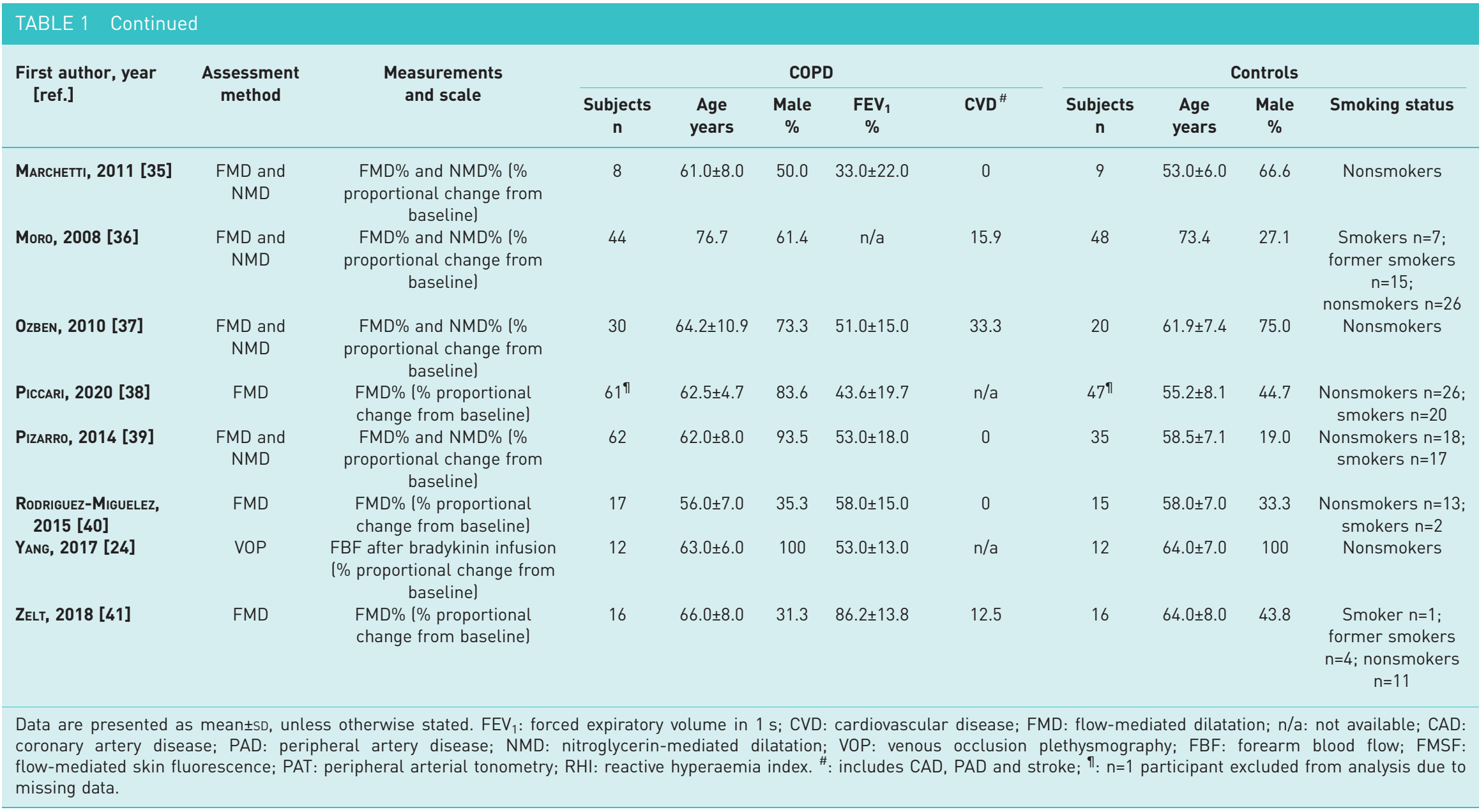




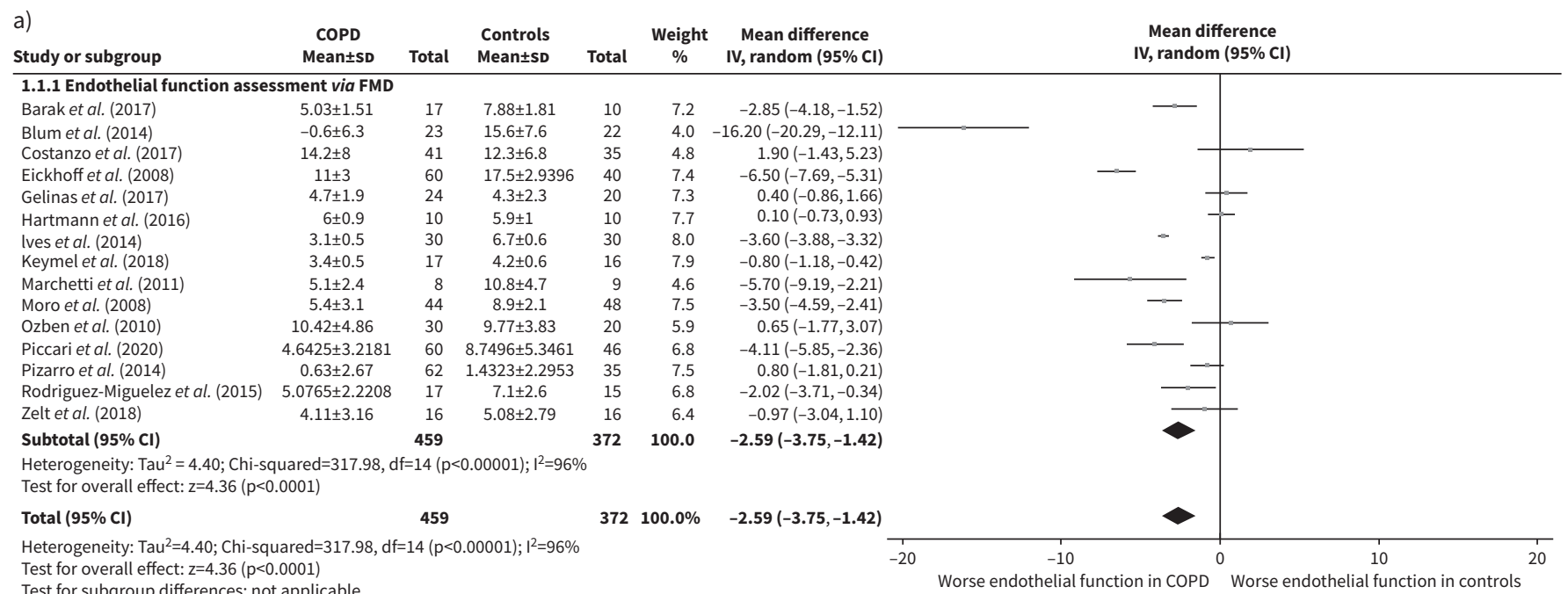

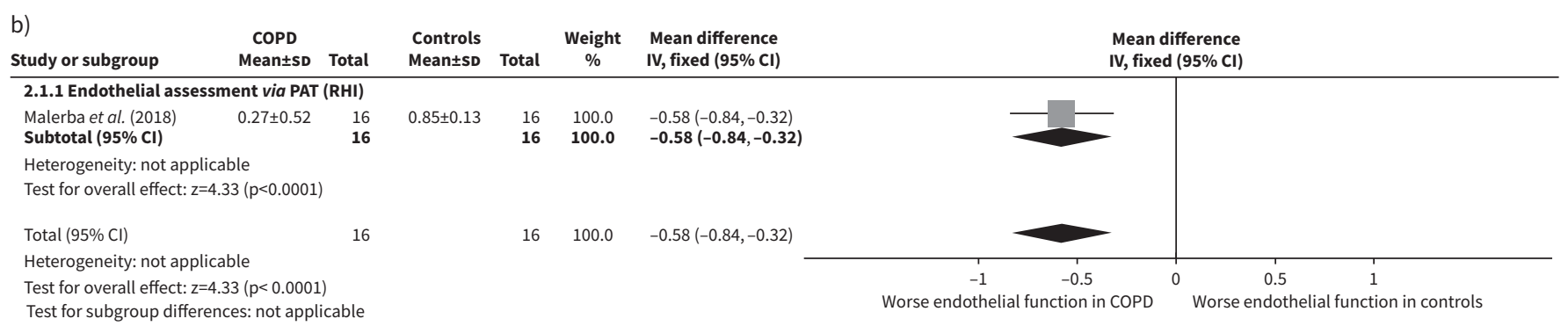

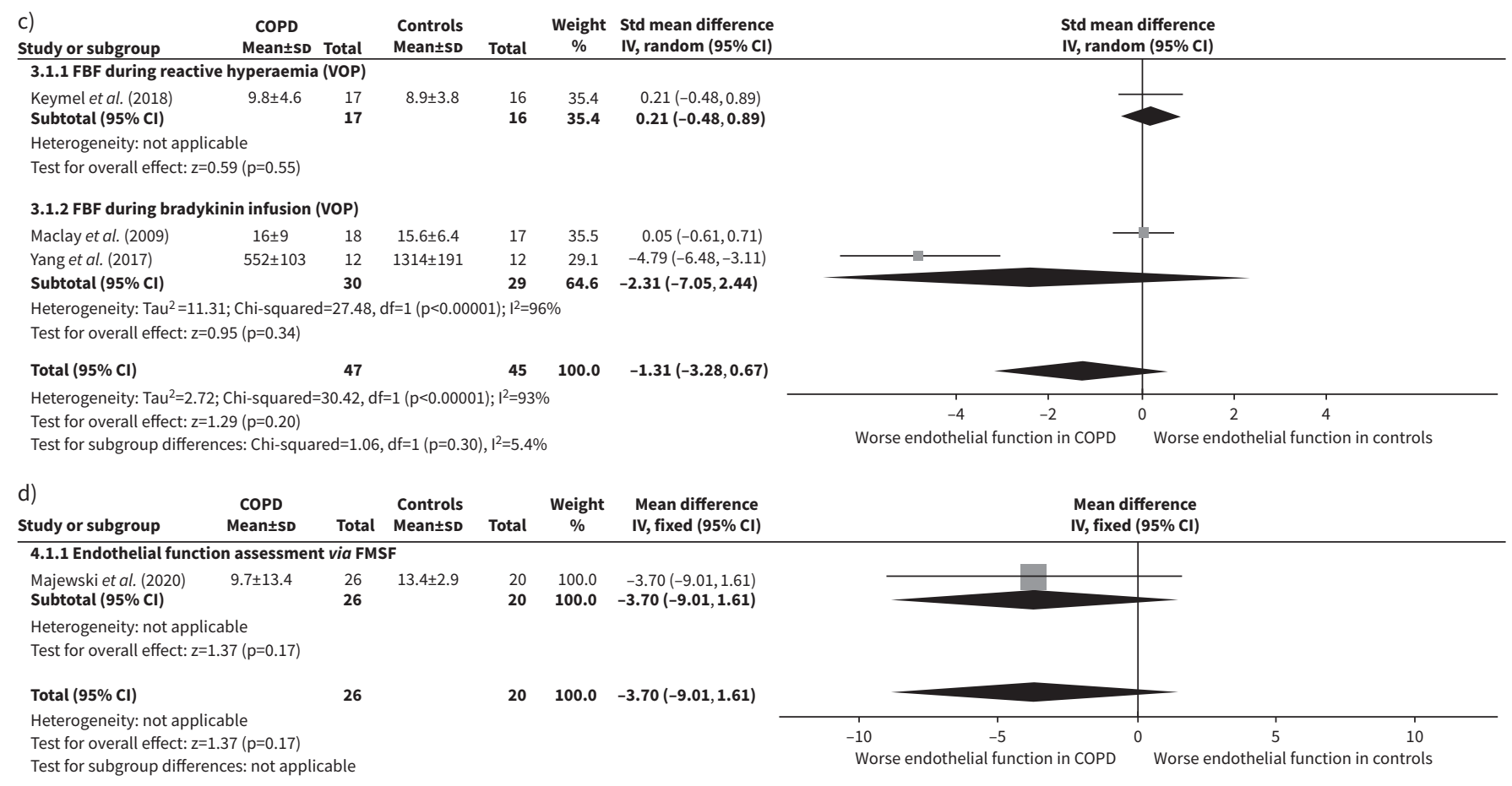

FIGURE 1 Forest plot of the difference in a) flow-mediated dilatation (FMD\%); b) reactive hyperaemia index (RHI), assessed by peripheral arterial tonometry (PAT); c) forearm blood flow (FBF) assessed by venous occlusion plethysmography (VOP); and d) reactive hyperaemia assessed using flow-mediated skin fluorescence (FMSF), among patients with COPD and non-COPD controls. 


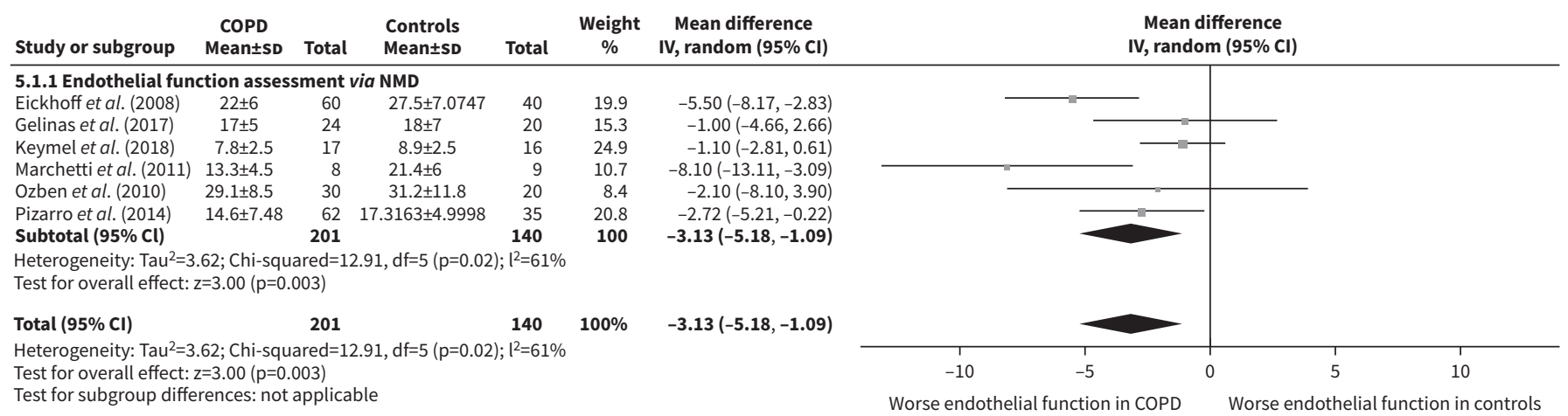

FIGURE 2 Forest plot of the difference in nitroglycerine-mediated dilatation (NMD\%) among patients with COPD and non-COPD controls.

\section{Endothelial function assessment via NMD}

Across six studies evaluating endothelium-independent vasodilation by the use of NMD, a significantly impaired response by WMD -3.13 (95\% CI -5.18 to -1.09 ) was observed in patients with COPD compared to controls, with moderate heterogeneity $\left(\mathrm{I}^{2}=61 \%, \mathrm{p}=0.02\right)$ (figure 2 ).

\section{Endothelial function assessment via all methods (pooled analysis)}

When pooling all studies together, regardless of the type of method used for assessment of vascular reactivity, pronounced endothelial dysfunction was observed in patients with COPD compared to non-COPD controls (SMD $-1.19,95 \% \mathrm{CI}-1.69$ to -0.68$)$, but with high heterogeneity $\left(\mathrm{I}^{2}=92 \%, \mathrm{p}<0.00001\right)$ (figure 3 ).

\section{Subgroup analysis}

In order to explore the heterogeneity across the included studies, subgroup analysis comparing endothelial function according to smoking status of controls was performed (figure 4). In the 12 studies comparing patients with COPD and nonsmoking controls, a more prominent endothelial dysfunction was evident in patients with COPD compared to nonsmoking controls (SMD $-1.75,95 \% \mathrm{CI}-2.58$ to $-0.92 ; \mathrm{I}^{2}=93 \%$, $\mathrm{p}<0.00001$ ), while no significant differences were observed between patients with COPD and smoking controls (SMD $-0.78,95 \%$ CI -1.87 to $0.32 ; \mathrm{I}^{2}=89 \%, \mathrm{p}<0.0001$ ).

Moreover, we performed subgroup analyses according to the presence of CAD. Supplementary table 4 includes definitions used in the various studies for CAD and cardiovascular disease (CVD), whether CAD or CVD were inclusion/exclusion criteria, and the percentage of patients receiving common vasoactive medications. Analysis of nine studies including patients with COPD and controls without CAD showed a

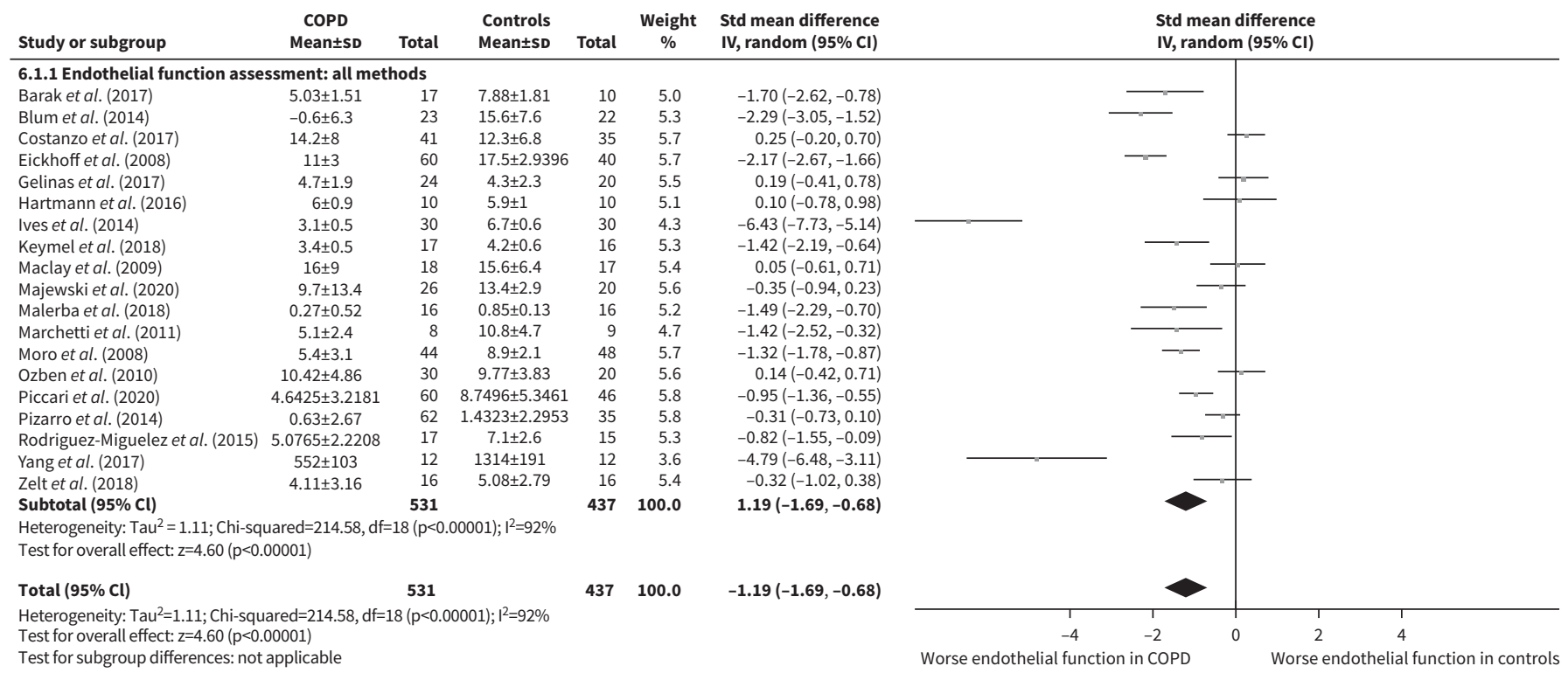

FIGURE 3 Forest plot of the difference in endothelial function among patients with COPD and non-COPD controls (all methods). 


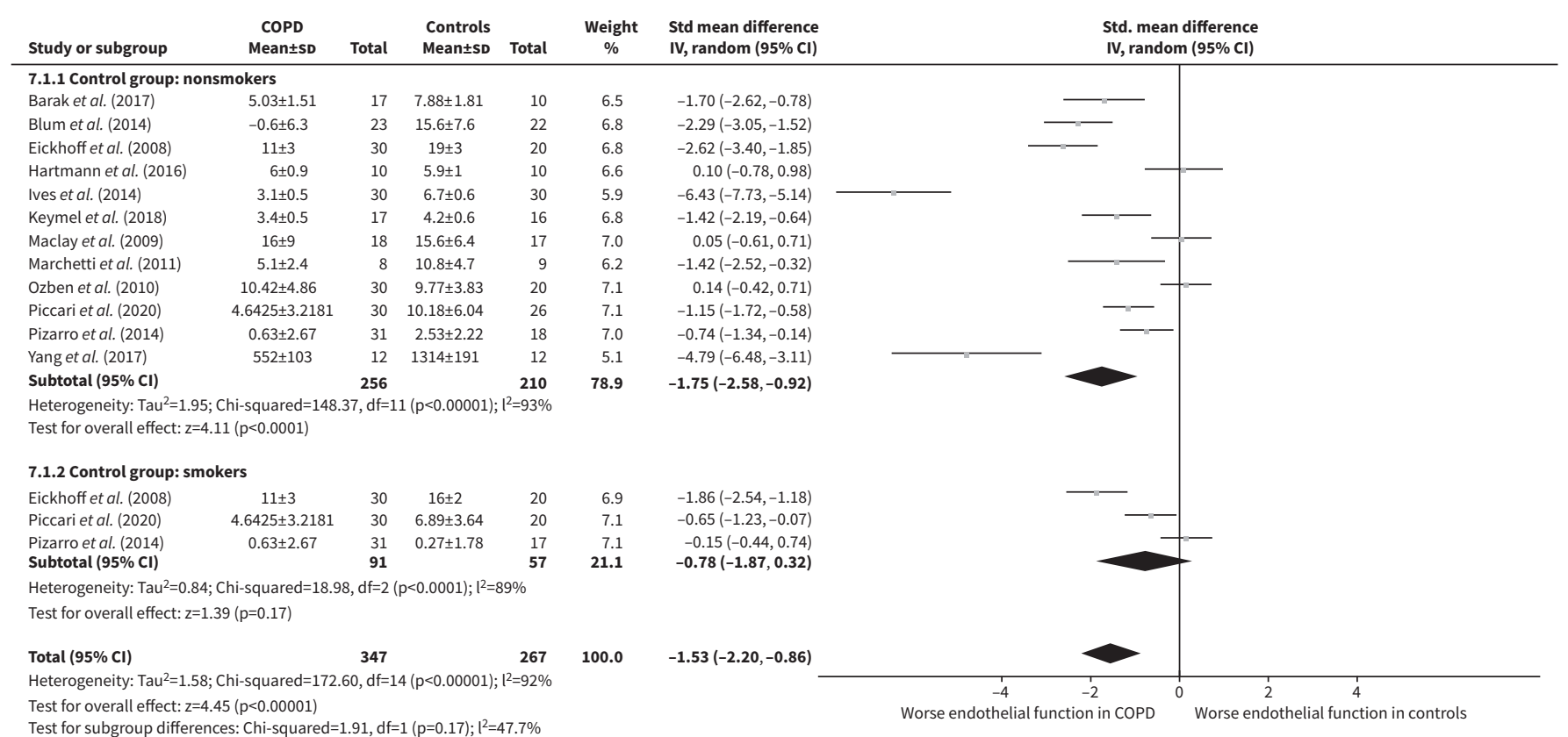

FIGURE 4 Subgroup analysis comparing endothelial function of patients with COPD with nonsmoking and smoking controls.

marginal, but not significant, impairment in endothelial function in COPD compared to controls (SMD $-0.61,95 \%$ CI -1.23 to $0.01 ; \mathrm{I}^{2}=89 \%, \mathrm{p}<0.00001$ ), while data from one study including patients with COPD and controls with CAD report a more prominent impairment in endothelial function in COPD than controls (supplementary figure 3). Finally, when pooling studies including only male participants, a marginally impaired endothelial function in patients with COPD compared to controls was noted (supplementary figure 4).

\section{Sensitivity analysis}

We repeated the main analysis by including only the high-quality studies (NOS score $\geqslant 7$ ) in order to explore the robustness of our findings. Of interest, after excluding studies classified as being of low quality, presence of a similarly impaired endothelial function in patients with COPD compared to controls was confirmed (SMD -1.20 , 95\% CI -1.76 to -0.65 ) (supplementary figure 5).

\section{Discussion}

This is the first systematic review of the assessment of endothelial function using almost all available functional methods in patients with COPD. The main finding of the present analysis is that patients with COPD have significantly impaired endothelial function compared with non-COPD controls. Sensitivity analysis excluding poor quality studies confirmed the main results. The observed difference in endothelial function is more pronounced when patients with COPD are compared to controls that are nonsmokers. Furthermore, the difference was slightly more pronounced when patients with COPD and CAD were compared to controls.

Endothelium is the single cell layer that lines the interior surface of the vascular system and it is involved in multiple mechanisms of vascular homeostasis, including regulation of vasomotor tone, vascular permeability, haemostasis, angiogenesis and innate and adaptive immunity [44]. Endothelial dysfunction is the basis of atherosclerosis and a trigger of cardiovascular outcomes in several cohort studies [15, 45-47]. Reduced nitric oxide (NO) is the hallmark of endothelial dysfunction; it may result either from decreased endothelial NO-synthase (eNOS) activity (due to endo/exogenous inhibitors, e.g. asymmetric dimethylarginine, or due to reduction in L-arginine) or from decreased NO-bioavailability (e.g. due to endothelin-1 overexpression) [48-50]. Existing evidence supports that oxidative stress and inflammation lead also to decreased NO-bioavailability and endothelial dysfunction [51], and probably, this pathway plays central role in endothelial damage in patients with COPD [9]. In particular, several studies indicated a significant association between COPD and inflammatory biomarkers (i.e. high-sensitivity C-reactive protein, fibrinogen, tumour necrosis factor- $\alpha$, etc.) [52], even in moderate COPD [53]. Worsening systemic inflammation is related to COPD severity, as well as greater morbidity and mortality [7]. Moreover, preliminary evidence showed that angiotensin-2 induces endothelial damage and vascular inflammation, 
suggesting that the renin-angiotensin system plays a significant role in endothelial damage [15, 48, 54]. Finally, insulin resistance is another pathway that is disturbed in patients with COPD [55] and is suggested to play a crucial role in endothelial dysfunction [48]. In states of insulin resistance, insulin signalling is altered, resulting in a dramatical downregulation of eNOS activity, whereas hyperglycaemia leads to increase of advanced glycation end-products, which are shown to promote vascular inflammation and oxidative excess, quench NO and impair endothelial function $[48,49]$.

As mentioned earlier, several functional techniques have been used in research works to evaluate endothelial integrity in populations with high burden of cardiovascular disease, including those with COPD [56]. VOP was one of the first techniques for endothelial function assessment, but it is currently rarely used due to its semi-invasive nature [56]. For several years, FMD has been considered the reference method, as it is noninvasive, cheap and strongly correlated with coronary function and cardiovascular outcomes [15, 56, 57]. However, its application in everyday clinical practice can be challenging, as it requires good standardisation, adherence to strict protocols, experienced operators and controlled environment (quiet room, stable temperature, etc.) $[15,57,58]$. PAT is used for assessment of endothelial function of the microvasculature; it is noninvasive, reproducible, operator-independent and shows strong correlation with outcomes [15]. However, it can be affected by environmental factors (temperature, light, etc.), whereas increased sympathetic tone (which is common among patients with COPD) has been suggested to impact the PAT signal [59]. More recent technologies evaluating skin or sublingual microcirculation are promising, as they are noninvasive and can be combined with several reactivity tests or exercise; however, only a few studies examined their correlations with coronary endothelial function and adverse outcomes [14]. In addition, it should be noted that all the aforementioned techniques require patient preparation (abstinence from smoking, caffeine, etc.) and collaboration during the test (lying still for some minutes); although quite simple, these tasks may be demanding for some patients with COPD, such as those with frequent cough, the very obese and others.

In line with our review, other studies have established a link between endothelial damage and COPD. In a previous systematic review, YE et al. [3] showed that patients with COPD had higher markers of endothelial function, arterial stiffness and other markers of subclinical cardiovascular disease, independently of smoking status. In the aforementioned systematic review and meta-analysis from Ambrosino et al. [17], patients with COPD showed a significantly lower FMD and NMD; FMD impairment was associated with age and forced expiratory volume in $1 \mathrm{~s}$. In another meta-analysis of similar design, VAEs et al. [18] confirmed the above results, showing a decline in both endothelial-dependent and -independent vasodilation of the forearm, as assessed by FMD. Overall, our results extend the prior evidence, as they are indicative of a large difference in endothelial function between patients with COPD and non-COPD controls (SMD $-1.19,95 \%$ CI -1.19 to -0.68 ), not only in the conduit arteries (as assessed by FMD), but also in the microvasculature (as assessed by the other aforementioned methods). The association between FMD and coronary endothelial function is well established [15]; however, more recent original works demonstrated that microvascular dysfunction is also strongly associated with cardiovascular risk factors [60], suggesting that these methods should be used to complement each other, as they measure different aspects of vascular biology [15].

In addition, our subgroup analysis showed significantly worse endothelial function in patients with COPD compared to nonsmoking controls, but this association was less prominent when patients with COPD were compared to smoking individuals. Smoking is closely associated with endothelial damage, as oxidative stress, systemic inflammation and impaired NO-bioavailability were considered to be related with cigarette smoking [61]. In fact, Cur et al. [62] demonstrated that current smokers have significantly lower FMD compared with never-smokers, and this association was dependent upon the total pack-years; chronic smokers with $\geqslant 40$ packyears had an approximately two-fold higher prevalence of low FMD than never-smokers. Although smoking is a major cardiovascular factor that plays a predominant role in the atherosclerotic process, it might not fully explain the high cardiovascular risk in COPD [63]. Moreover, in the previous work from AMBrosino et al. [17], the relationship between COPD and endothelial function was independent of baseline smoking status.

To our knowledge, the present systematic review and meta-analysis is the largest effort in this field, including 19 studies and using the vast majority of the available functional methods of endothelial function evaluation in COPD. It followed a careful literature search and a rigorous methodology; we attempted to elucidate design errors detected in previous meta-analyses (e.g. double counts and units-of-analysis errors) in this field. However, our work has some limitations that have to be acknowledged. First, there was significant heterogeneity across the studies included; we attempted to minimise the extent that it might affect our results by using the random-effects model, as well as by performing a number of subgroup analyses. In some of our subgroup analyses, such as three of the four analyses by the specific functional method used (PAT, VOP, FMSF) or the analysis in male patients, the number of included studies were small and, thus, did not allow us to draw firm conclusions. In addition, there was a difference in the percentages of patients receiving vasoactive medications in some of the 
included studies and it is not known to what extent these mismatches interfere with our findings. Our search was restricted to English-language journals; hence we may have introduced publication bias. Finally, although we tried extensively to retrieve missing data by contacting authors of the primary studies, we could not use data from a few studies due to missing values.

In conclusion, the present meta-analysis showed that patients with COPD have impaired endothelial function compared to controls without COPD. Considering the bidirectional relationship between endothelial damage and cardiovascular disease, future large and properly designed studies are needed to shed more light in this field, first by examining associations of endothelial function with adverse cardiovascular outcomes specifically in patients with COPD and, second, by assessing the feasibility of performing these assessments in everyday clinical practice in this population.

Conflict of interest: None declared.

\section{References}

1 Adeloye D, Chua S, Lee C, et al. Global and regional estimates of COPD prevalence: systematic review and meta-analysis. J Glob Health 2015; 5: 020415.

2 World Health Organization (WHO). The Top 10 Causes of Death. https://www.who.int/news-room/fact-sheets/ detail/the-top-10-causes-of-death. Date last accessed: 24 December 2020

3 Ye C, Younus A, Malik R, et al. Subclinical cardiovascular disease in patients with chronic obstructive pulmonary disease: a systematic review. QJM 2017; 110: 341-349.

4 Sin DD, Wu L, Man SFP. The relationship between reduced lung function and cardiovascular mortality: a population-based study and a systematic review of the literature. Chest 2005; 127: 1952-1959.

5 Duong M, Islam S, Rangarajan S, et al. Mortality and cardiovascular and respiratory morbidity in individuals with impaired $\mathrm{FEV}_{1}$ (PURE): an international, community-based cohort study. Lancet Glob Health 2019; 7: e613-e623.

Barnes PJ. Chronic obstructive pulmonary disease: effects beyond the lungs. PLoS Med 2010; 7: e1000220.

7 Brassington K, Selemidis S, Bozinovski S, et al. New frontiers in the treatment of comorbid cardiovascular disease in chronic obstructive pulmonary disease. Clin Sci 2019; 133: 885-904.

8 Morgan AD, Zakeri R, Quint JK. Defining the relationship between COPD and CVD: what are the implications for clinical practice? Ther Adv Respir Dis 2018; 12: 1753465817750524.

9 Polverino F, Celli BR, Owen CA. COPD as an endothelial disorder: endothelial injury linking lesions in the lungs and other organs? (2017 Grover Conference Series). Pulm Circ 2018; 8: 2045894018758528.

10 Herrera MD, Mingorance C, Rodríguez-Rodríguez R, et al. Endothelial dysfunction and aging: an update. Ageing Res Rev 2010; 9: 142-152.

11 Mercado N, Ito K, Barnes PJ. Accelerated ageing of the lung in COPD: new concepts. Thorax 2015; 70: 482-489.

12 Brandsma CA, de Vries M, Costa R, et al. Lung ageing and COPD: is there a role for ageing in abnormal tissue repair? Eur Respir Rev 2017; 26: 170073.

13 Zakynthinos E, Daniil Z, Papanikolaou J, et al. Pulmonary hypertension in COPD: pathophysiology and therapeutic targets. Curr Drug Targets 2011; 12: 501-513.

14 Theodorakopoulou MP, Schoina M, Sarafidis P. Assessment of endothelial and microvascular function in CKD: older and newer techniques, associated risk factors, and relations with outcomes. Am J Nephrol 2020; 51: 931-949.

15 Flammer AJ, Anderson T, Celermajer DS, et al. The assessment of endothelial function: from research into clinical practice. Circulation 2012; 126: 753-767.

16 Scherr A, Schumann DM, Karakioulaki M, et al. Endothelial dysfunction is not a predictor of outcome in chronic obstructive pulmonary disease. Respir Res 2020; 21: 90.

17 Ambrosino P, Lupoli R, Iervolino S, et al. Clinical assessment of endothelial function in patients with chronic obstructive pulmonary disease: a systematic review with meta-analysis. Intern Emerg Med 2017; 12: 877-885.

18 Vaes AW, Spruit MA, Theunis J, et al. Endothelial function in patients with chronic obstructive pulmonary disease: a systematic review of studies using flow mediated dilatation. Expert Rev Respir Med 2017; 11: 1021-1031.

19 Dipla K, Triantafyllou A, Grigoriadou I, et al. Impairments in microvascular function and skeletal muscle oxygenation in women with gestational diabetes mellitus: links to cardiovascular disease risk factors. Diabetologia 2017; 60: 192-201.

20 Herzog R, Álvarez-Pasquin MJ, Díaz C, et al. Are healthcare workers' intentions to vaccinate related to their knowledge, beliefs and attitudes? A systematic review. BMC Public Health 2013; 13: 154.

21 Hozo SP, Djulbegovic B, Hozo I. Estimating the mean and variance from the median, range, and the size of a sample. BMC Med Res Methodol 2005; 5: 13.

22 Higgins JPT, Thomas J, Chandler J, et al., eds. Cochrane Handbook for Systematic Reviews of Interventions. 2nd Edn. Chichester, John Wiley \& Sons, 2019.

23 Maclay JD, McAllister DA, Mills NL, et al. Vascular dysfunction in chronic obstructive pulmonary disease. Am J Respir Crit Care Med 2009; 180: 513-520.

24 Yang L, Cheriyan J, Gutterman DD, et al. Mechanisms of vascular dysfunction in COPD and effects of a novel soluble epoxide hydrolase inhibitor in smokers. Chest 2017; 151: 555-563.

25 Keymel S, Schueller B, Sansone R, et al. Oxygen dependence of endothelium-dependent vasodilation: importance in chronic obstructive pulmonary disease. Arch Med Sci 2018; 14: 297-306.

26 Malerba M, Radaeli A, Nardin M, et al. Endothelial dysfunction assessment by noninvasive peripheral arterial tonometry in patients with chronic obstructive pulmonary disease compared with healthy subjects. Clin Respir J 2018; 12: 1466-1472.

27 Majewski S, Szewczyk K, Białas AJ, et al. Assessment of microvascular function in vivo using flow mediated skin fluorescence (FMSF) in patients with obstructive lung diseases: a preliminary study. Microvasc Res 2020; 127: 103914.

28 Blum A, Simsolo C, Sirchan R. Vascular responsiveness in patients with chronic obstructive pulmonary disease (COPD). Eur J Intern Med 2014; 25: 370-373. 

chronic obstructive pulmonary disease. Aging Clin Exp Res 2017; 29: 157-164. moderate-severe chronic obstructive pulmonary disease. Sci Rep 2017; 7: 16929.

31 Eickhoff P, Valipour A, Kiss D, et al. Determinants of systemic vascular function in patients with stable chronic obstructive pulmonary disease. Am J Respir Crit Care Med 2008; 178: 1211-1218.

32 Gelinas JC, Lewis NC, Harper MI, et al. Aerobic exercise training does not alter vascular structure and function in chronic obstructive pulmonary disease. Exp Physiol 2017; 102: 1548-1560.

33 Hartmann SE, Waltz X, Leigh R, et al. Blood flow during handgrip exercise in COPD: effect of vitamin C. Med Sci Sports Exerc 2016; 48: 200-209.

34 Ives SJ, Harris RA, Witman MAH, et al. Vascular dysfunction and chronic obstructive pulmonary disease: the role of redox balance. Hypertension 2014; 63: 459-467.

35 Marchetti N, Ciccolella DE, Jacobs MR, et al. Hospitalized acute exacerbation of COPD impairs flow and nitroglycerin-mediated peripheral vascular dilation. COPD 2011; 8: 60-65.

36 Moro L, Pedone C, Scarlata S, et al. Endothelial dysfunction in chronic obstructive pulmonary disease. Angiology 2008; 59: 357-364.

37 Ozben B, Eryüksel E, Tanrikulu AM, et al. Acute exacerbation impairs endothelial function in patients with chronic obstructive pulmonary disease. Turk Kardiyol Dern Ars 2010; 38: 1-7.

38 Piccari L, Del Pozo R, Blanco I, et al. Association between systemic and pulmonary vascular dysfunction in COPD. Int J Chron Obstruct Pulmon Dis 2020; 15: 2037-2047.

39 Pizarro S, García-Lucio J, Peinado VI, et al. Circulating progenitor cells and vascular dysfunction in chronic obstructive pulmonary disease. PLoS One 2014; 9: e106163.

40 Rodriguez-Miguelez P, Seigler N, Bass L, et al. Assessments of endothelial function and arterial stiffness are reproducible in patients with COPD. Int J Chron Obstruct Pulmon Dis 2015; 10: 1977-1986.

41 Zelt JT, Jones JH, Hirai DM, et al. Systemic vascular dysfunction is associated with emphysema burden in mild COPD. Respir Med 2018; 136: 29-36.

42 Barr RG, Mesia-Vela S, Austin JHM, et al. Impaired flow-mediated dilation is associated with low pulmonary function and emphysema in ex-smokers: the Emphysema and Cancer Action Project (EMCAP) Study. Am J Respir Crit Care Med 2007; 176: 1200-1207.

43 Kuzubova NA, Chukhlovin AB, Morozova EB, et al. Common intronic D variant of ACE gene is associated with endothelial dysfunction in COPD. Respir Med 2013; 107: 1217-1221.

44 Aird WC. Phenotypic heterogeneity of the endothelium: I. Structure, function, and mechanisms. Circ Res 2007; 100: 158-173.

45 Yeboah J, Folsom AR, Burke GL, et al. Predictive value of brachial flow-mediated dilation for incident cardiovascular events in a population-based study: the multi-ethnic study of atherosclerosis. Circulation 2009; 120: 502-509.

46 Huang AL, Silver AE, Shvenke E, et al. Predictive value of reactive hyperemia for cardiovascular events in patients with peripheral arterial disease undergoing vascular surgery. Arterioscler Thromb Vasc Biol 2007; 27: 2113-2119.

47 Anderson TJ, Charbonneau F, Title LM, et al. Microvascular function predicts cardiovascular events in primary prevention: long-term results from the Firefighters and Their Endothelium (FATE) study. Circulation 2011; 123: $163-169$.

48 Endemann DH, Schiffrin EL. Endothelial dysfunction. J Am Soc Nephrol 2004; 15: 1983-1992.

49 Sarafidis PA, Bakris GL. Review: insulin and endothelin: an interplay contributing to hypertension development? J Clin Endocrinol Metab 2007; 92: 379-385.

50 Gimbrone Michael A, García-Cardeña G. Endothelial cell dysfunction and the pathobiology of atherosclerosis. Circ Res 2016; 118: 620-636.

51 Heitzer T, Schlinzig T, Krohn K, et al. Endothelial dysfunction, oxidative stress, and risk of cardiovascular events in patients with coronary artery disease. Circulation 2001; 104: 2673-2678.

52 Gan WQ, Man SFP, Senthilselvan A, et al. Association between chronic obstructive pulmonary disease and systemic inflammation: a systematic review and a meta-analysis. Thorax 2004; 59: 574-580.

53 Sin DD, Man SFP. Why are patients with chronic obstructive pulmonary disease at increased risk of cardiovascular diseases? The potential role of systemic inflammation in chronic obstructive pulmonary disease Circulation 2003; 107: 1514-1519.

54 Schiffrin EL, Park JB, Pu Q. Effect of crossing over hypertensive patients from a beta-blocker to an angiotensin receptor antagonist on resistance artery structure and on endothelial function. J Hypertens 2002; 20: 71-78.

55 Urban MH, Ay L, Funk GC, et al. Insulin resistance may contribute to vascular dysfunction in patients with chronic obstructive pulmonary disease. Wien Klin Wochenschr 2014; 126: 106-112.

56 Deanfield JE, Halcox JP, Rabelink TJ. Endothelial function and dysfunction: testing and clinical relevance. Circulation 2007; 115: 1285-1295.

57 Lekakis J, Abraham P, Balbarini A, et al. Methods for evaluating endothelial function: a position statement from the European Society of Cardiology Working Group on Peripheral Circulation. Eur J Cardiovasc Prev Rehabil 2011; 18: 775-789.

58 Stout M. Flow-mediated dilatation: a review of techniques and applications. Echocardiography 2009; 26: 832-841.

59 Hedetoft M, Olsen NV. Evaluation of endothelial function by peripheral arterial tonometry and relation with the nitric oxide pathway. Nitric Oxide 2014; 42: 1-8.

60 Hamburg NM, Palmisano J, Larson MG, et al. Relation of brachial and digital measures of vascular function in the community: the Framingham Heart Study. Hypertension 2011; 57: 390-396.

61 Lynch J, Jin L, Richardson A, et al. Tobacco smoke and endothelial dysfunction: role of aldehydes? Curr Hypertens Rep 2020; 22: 73.

62 Cui M, Cui R, Liu K, et al. Associations of tobacco smoking with impaired endothelial function: the circulatory risk in communities study (CIRCS). J Atheroscler Thromb 2018; 25: 836-845.

63 Stone IS, Barnes NC, Petersen SE. Chronic obstructive pulmonary disease: a modifiable risk factor for cardiovascular disease? Heart 2012; 98: 1055-1062. 